\title{
Morfoanatomia da raiz tuberosa de Vernonia oxylepis Sch. Bip. in Mart. ex Baker - Asteraceae ${ }^{1}$
}

\author{
Divina Aparecida Anunciação Vilhalva² e Beatriz Appezzato-da-Glória ${ }^{3,4}$
}

Recebido em 13/10/2005. Aceito em 3/02/2006

\begin{abstract}
RESUMO - (Morfoanatomia da raiz tuberosa de Vernonia oxylepis Sch. Bip. in Mart. ex Baker - Asteraceae). Várias espécies herbáceas e subarbustivas, nativas do Cerrado no Brasil, são geofitas, ou seja, sobrevivem ao período desfavorável de déficit hídrico e de baixas temperaturas, que muitas vezes coincide com incêndios, mantendo apenas a porção subterrânea. Vernonia oxylepis é uma dessas espécies e o objetivo desse estudo foi descrever a morfoanatomia da raiz tuberosa e a formação das gemas nessa raiz. Tal raiz é constituída de um eixo orientado perpendicularmente no solo, a partir do qual ramos aéreos são formados na porção proximal, situada ao nível do solo, ao longo do ciclo de vida da planta. Na porção proximal da raiz ocorre auto-enxertia da base dos ramos por ela emitidos. A raiz acumula lipídios e frutanos, apresenta ligeira contração e forma gemas reparativas; a formação das gemas adventícias se dá a partir do periciclo proliferado. Tais características poderiam ser associadas ao processo de adaptação da espécie às condições do Cerrado.
\end{abstract}

Palavras-chave: Cerrado, frutanos, gemas, reservas, raízes tuberosas

ABSTRACT - (Morpho-anatomy of the tuberous root of Vernonia oxylepis Sch. Bip. in Mart. ex Baker - Asteraceae). Several native herbaceous and subshrub species native to the Cerrado in Brazil are geophytes, that is, they survive the unfavorable dry season and low temperatures, that sometimes coincide with fire, with only the underground system intact. Vernonia oxylepis is one of these species and the aim of this study was to describe the morpho-anatomy of the tuberous root and bud formation on this structure. The main axis of this root is perpendicular to the soil surface, and from which aerial shoots arise periodically throughout the life cycle. On the upper portion of the root, self-grafting of the shoots occurs. The root stores lipids and fructans, exhibits contraction and produces reparatory buds; adventitious buds arise from proliferated pericycle. These characteristics may be related to adaptation of this species to conditions in the Cerrado.

Key words: Cerrado, fructans, buds, storage, tuberous roots

\section{Introdução}

A família Asteraceae vem se destacando como a mais freqüente entre as espécies do estrato herbáceo e subarbustivo do Cerrado (Almeida et al. 2005). Essa apresenta vários tipos de sistemas subterrâneos espessados e gemíferos, tais como os xilopódios, descritos por Paviani $(1972 ; 1977 ; 1978 ; 1987)$, em Brasilia sickii G.M. Barroso e os rizóforos descritos em espécies de Vernonia Schreb. por Sajo \& Menezes (1986a; 1986b) e por Hayashi \& Appezzato-da-Glória (2005). Considerando essa diversidade morfoanatômica dos sistemas subterrâneos dessa família e que esses são pouco conhecidos, estudos anatômicos mostram-se de fundamental importância para a identificação de sua natureza estrutural (Appezzatoda-Glória 2003).

Rizzini (1965), analisando a regeneração de plantas do Cerrado, sujeitas à ação do fogo e do homem, ressaltou o papel da formação de gemas nas raízes na sobrevivência das espécies, particularmente, em regiões secas. Segundo o autor, ao contrário das sementes, as raízes gemíferas encontram-se protegidas no solo e proporcionam nutrição para o desenvolvimento das gemas. Diferentes sítios de origem de gemas a partir de raízes têm sido relatados na literatura e estão relacionados com a capacidade de sobrevivência das espécies ao ambiente (Hayashi et al. 2001). Em Mandevilla illustris (Vell.) Woodson e M. velutina (Mart. ex Stadelm.) Woodson

\footnotetext{
1 Parte da Tese de Mestrado da primeira Autora, vinculada ao Programa de Pós-Graduação em Biologia Vegetal da Universidade Estadual de Campinas

2 Universidade Estadual de Campinas, Departamento de Botânica, C. Postal 6109, 13083-970 Campinas, SP, Brasil

3 Universidade de São Paulo, Escola Superior de Agricultura Luiz de Queiroz, Departamento de Ciências Biológicas, C. Postal 09, 13418-900 Piracicaba, SP, Brasil

4 Autor para correspondência: bagloria@esalq.usp.br
} 
(Apocynaceae) novos ramos são formados a partir do xilopódio e, esporadicamente, a partir da porção proximal da raiz tuberosa (Appezzato-da-Glória \& Estelita-Teixeira 1995; 2000).

Muitas espécies do Cerrado possuem sistemas subterrâneos gemíferos que acumulam grandes quantidades de frutanos (Figueiredo-Ribeiro et al. 1986; Tertuliano \& Figueiredo-Ribeiro 1993). Segundo Asega \& Carvalho (2004), o conteúdo desses carboidratos nos rizóforos de Vernonia herbacea varia de acordo com a fenologia da planta. Os frutanos, além de atuarem como compostos de reserva podem estar relacionados à tolerância das plantas a estresses ambientais como a seca (Vijn \& Smeekens 1999) e as baixas temperaturas (Figueiredo-Ribeiro 1993; Alberdi et al. 2002), pois atuam no controle da osmorregulação devido às rápidas relações de polimerização e despolimerização (Figueiredo-Ribeiro 1993).

Esse trabalho teve por objetivo descrever a morfoanatomia da raiz tuberosa e a formação das gemas em Vernonia oxylepis Sch. Bip. in Mart. ex Baker, espécie herbácea, perene e nativa do Cerrado, a qual acumula frutanos em seu sistema subterrâneo.

\section{Material e métodos}

Vernonia oxylepis Sch. Bip. in Mart. ex Baker foi coletada numa área de campos sujos, na Estação Ecológica de Itirapina, entre os seguintes pontos de coordenadas $22^{\circ} 13^{\prime} 20^{\prime}$ 'S e 47 $54^{\prime} 13^{\prime \prime} \mathrm{W}$; $22^{\circ} 13^{\prime} 54^{\prime \prime} \mathrm{S}$

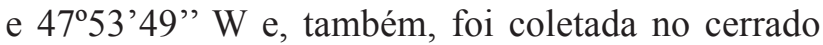
Graúna, no município de Itirapina, no seguinte ponto de coordenada: $22^{\circ} 15^{\prime} 46^{\prime \prime} \mathrm{S}$ e $47^{\circ} 47^{\prime} 58^{\prime \prime} \mathrm{W}$. A identificação foi feita por especialista e as exsicatas foram registradas e incorporadas ao acervo do Herbário da Escola Superior de Agricultura 'Luiz de Queiroz' (ESA) da Universidade de São Paulo, sob os seguintes registros: ESA 83396, 83399, 83400 e 84359.

Para a análise anatômica porções do sistema subterrâneo contendo gemas foram retiradas e fixadas em FAA 50 (Johansen 1940) e levadas a uma bomba de vácuo para a retirada do ar do material. Após a fixação as amostras foram desidratadas em série etílica, infiltradas com a resina metacrilato da Leica, seccionadas a $5 \mathrm{~mm}$ de espessura, coradas com azul de toluidina $0,05 \%$ em tampão fosfato e ácido cítrico pH 4,5 (Sakai 1973) e montadas em resina sintética "Entellan". Para visualizar a endoderme na raiz tuberosa foram realizados cortes à mão-livre e posteriormente clarificados com hipoclorito de sódio a
$20 \%$, lavados com água destilada, corados com Azul de Astra e Fucsina Básica (Roeser 1972), desidratados através da série etílica e acetato de butila 50 e 100\%, sendo as lâminas montadas com resina sintética.

Testes microquímicos foram realizados utilizando-se amostras não fixadas. Os cortes foram feito à mão-livre com auxílio de lâmina de barbear. $\mathrm{O}$ Sudan IV (Jensen 1962) foi empregado para visualizar as substâncias lipofílicas, o cloreto de zinco iodado (Strasburger 1913) para detectar a presença de amido e o cloreto férrico (Johansen 1940) para verificar a presença de compostos fenólicos.

Para evidenciar os cristais de inulina, as amostras foram tratadas em álcool etílico $70 \%$ por 2 a 4 dias, sendo os cortes observados em microscópio de luz polarizada e também submetidos ao timol 15\% em solução alcoólica e ácido sulfúrico concentrado (Johansen 1940).

\section{Resultados}

O sistema subterrâneo de Vernonia oxylepis é constituído por um eixo longo orientado perpendicularmente em relação à superfície do solo, com aproximadamente $19 \mathrm{~cm}$ de comprimento por 0,6 $\mathrm{cm}$ de largura, cujos ramos aéreos são formados na porção proximal (Fig. 1, 3, 4). O eixo, de consistência carnosa, apresenta várias áreas de contração (Fig. 2, 7) e pequenas protuberâncias (Fig. 11,13) ao longo de toda a sua superfície. Embora as protuberâncias sejam morfologicamente idênticas (Fig. 11, 13) os cortes longitudinais da raiz tuberosa passando pelas mesmas (Fig. 12, 14) permitem observar que, quando existe um traço vascular conectando a protuberância ao cilindro vascular do eixo de origem (Fig. 14), trata-se de raiz lateral e, quando não há esse traço vascular chegando ao cilindro central da raiz (Fig. 12), trata-se de gema (Fig. 16).

As análises anatômicas revelam que a porção proximal do sistema subterrâneo de V. oxylepis apresenta eixos caulinares auto-enxertados (Fig. 3, 4). O restante do sistema é uma raiz, pois no centro da estrutura observa-se o xilema primário com maturação centrípeta (Fig. 5, 6). Os testes histoquímicos revelam que esta raiz tuberosa acumula grande quantidade de gotas lipídicas nas células parenquimáticas resultantes da proliferação do periciclo (Fig. 9) e também cristais de inulina observados sob luz polarizada (Fig. 10). A raiz não acumula amido ou compostos fenólicos, pois o resultado dos testes com os reagentes cloreto de zinco iodado e cloreto férrico foi negativo. 

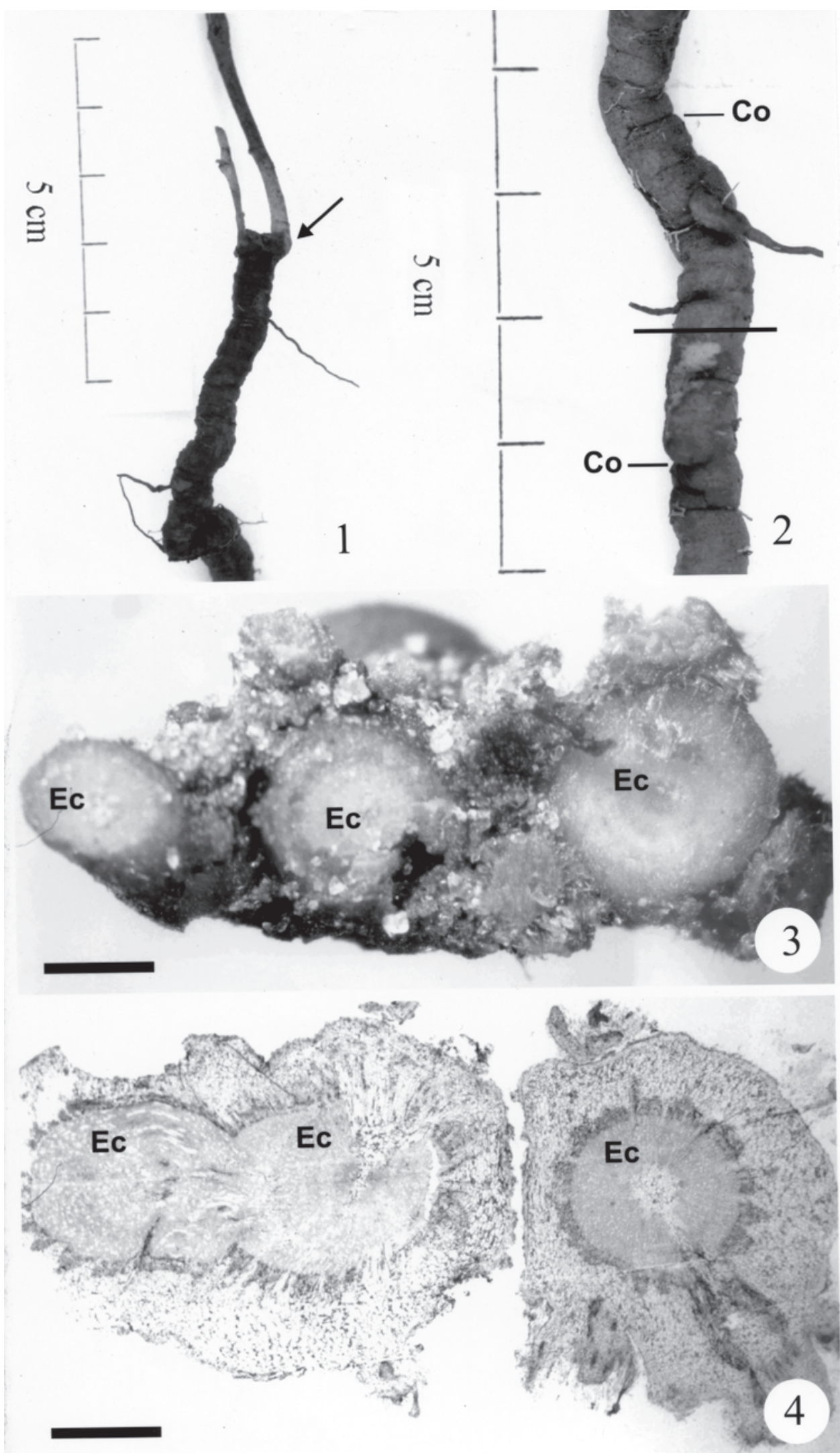

Figuras 1-4. Vernonia oxylepis Sch. Bip. in Mart. ex Baker. 1. Porção proximal da raiz tuberosa com ramos aéreos (seta) na qual foram feitos as secções transversais mostrados nas figuras 3 e 4. 2. Detalhe da raiz tuberosa com áreas de contração (Co). $\mathrm{O}$ traço indica a região seccionada transversalmente e ilustrada na figura 5. 3. Secção transversal da porção proximal da raiz tuberosa mostrando a saída de três eixos caulinares $(\mathrm{Ec})$. 4. Secção transversal da estrutura mostrada na figura anterior. Barras $=730 \mu \mathrm{m}(3) ; 536 \mu \mathrm{m}(4)$. 

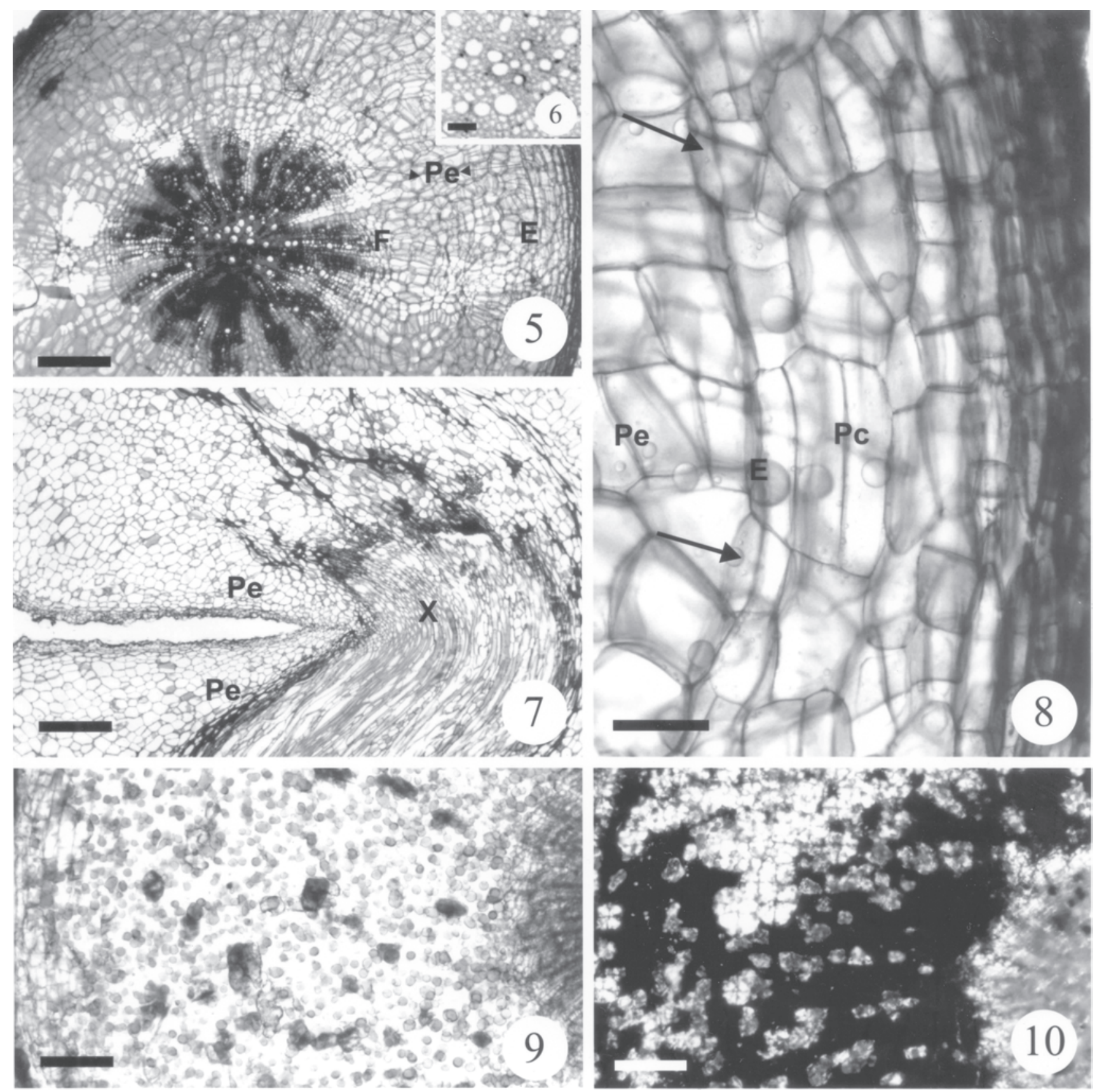

Figuras 5-10. Vernonia oxylepis Sch. Bip. in Mart. ex Baker. 5. Secção transversal da raiz tuberosa na região indicada pelo traço na figura 2. Observar a endoderme $(\mathrm{E})$ e cilindro vascular sólido com periciclo proliferado $(\mathrm{Pe}) . \mathrm{F}=$ floema secundário. 6 . Detalhe do xilema primário da figura anterior. 7. Secção longitudinal da região da contração radicular. Observar o número de camadas do periciclo proliferado (Pe). $\mathrm{X}=$ xilema secundário. 8. Detalhe da figura 5 mostrando a endoderme (E) provida de estrias de Caspary (setas). Pc $=$ parênquima cortical, $\mathrm{Pe}=$ periciclo proliferado. 9. Gotas lipídicas coradas com Sudan IV no periciclo proliferado. 10. Cristais de inulina visualizados sob luz polarizada. Barras $=230 \mu \mathrm{m}(5) ; 99,5 \mu \mathrm{m}(6) ; 37 \mu \mathrm{m}(8) ; 199 \mu \mathrm{m}(7,9,10)$. 

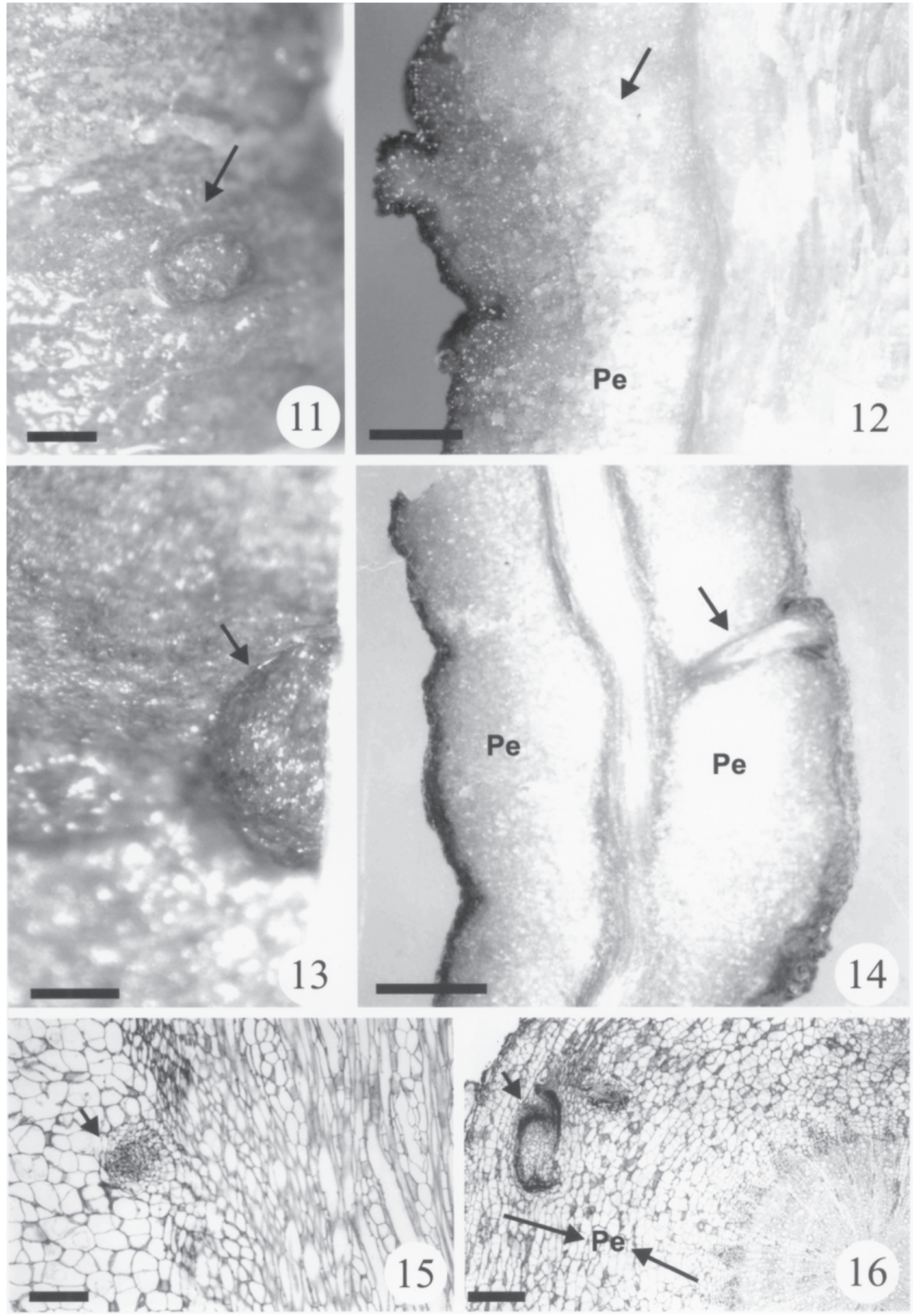

Figuras 11-16. Vernonia oxylepis Sch. Bip. in Mart. ex Baker. 11. Vista frontal de uma protuberância (seta). 12. Secção longitudinal da região com a protuberância na qual se observa a ausência de traço vascular (seta) chegando ao cilindro central da raiz. Pe $=$ periciclo proliferado. 13. Vista frontal de uma protuberância (seta). 14. Secção longitudinal da região com a protuberância que apresenta traço vascular (seta) chegando ao cilindro central da raiz. 15. Secção longitudinal da raiz tuberosa no qual se observa um primórdio de raiz lateral (seta) originado nas camadas mais internas do periciclo proliferado. 16. Secção transversal da raiz tuberosa mostrando a gema caulinar (seta) se originando nas camadas mais externas do periciclo proliferado (Pe). Observe que os traços vasculares não chegam ao cilindro central da raiz. Barras $=294 \mu \mathrm{m}(11-12) ; 188 \mu \mathrm{m}(13) ; 620 \mu \mathrm{m}(14) ; 74 \mu \mathrm{m}(15) ; 199 \mu \mathrm{m}(16)$. 
Observa-se a endoderme com estrias de Caspary (Fig. 8), confirmando que as várias camadas de células parenquimáticas subjacentes têm origem pericíclica. As gemas originam-se nas camadas mais externas deste periciclo proliferado (Fig. 16), enquanto os primórdios radiculares têm origem nas suas camadas mais internas (Fig. 15). Opostas às áreas de contração (Fig. 7), as células do periciclo são menores e o número de camadas do periciclo também é menor. Não são observadas estruturas secretoras no sistema subterrâneo.

\section{Discussão}

Em Vernonia oxylepis, o sistema subterrâneo é gemífero e a estrutura anatômica da maior parte do eixo é radicular, pois a maturação do xilema primário é centrípeta. A porção superior deste sistema, a qual apresenta ramos unidos por auto-enxertia, é muito diminuta e não lignificada, não podendo ser denominada xilopódio, conforme descrição de Rizzini \& Heringer (1961), para esta estrutura subterrânea. Portanto, neste estudo, considerou-se que, Vernonia oxylepis, possui raiz tuberosa gemífera sendo a tuberização resultante da proliferação do periciclo. Em Smallanthus sonchifolius a tuberização resulta da proliferação do parenquimático cortical (Machado et al. 2004) e, em Mandevilla illustris e M. velutina, a tuberização da raiz envolve atividade cambial, na qual é produzida grande proporção de parênquima vascular, em especial, o floemático (Appezzato-da-Glória \& Estelita-Teixeira 2000).

A contração radicular, verificada em Vernonia oxylepis, tem sido registrada em muitas outras espécies herbáceas perenes. Tal contração promove o autoenterramento da planta e, a ocorrência de gemas em regiões mais profundas do solo, resultante da contração radicular, parece indicar um mecanismo adaptativo às condições ambientais adversas (Appezzato-da-Glória 2003). O processo de contração radicular em $V$. oxylepis difere daquele descrito para a raiz tuberosa axial de Oxalis latifolia Kunth. (Oxalidaceae) por Estelita-Teixeira (1978). Segundo a autora, durante o processo de contração, fileiras radiais de células do parênquima floemático entram em colapso, se deformam e se inclinam de maneira tão acentuada que a fileira fica reduzida a uma linha, em geral, o xilema forma uma curvatura acompanhando a linha de células colapsadas. Em $V$. oxylepis há apenas a redução do número de camadas do periciclo, sem o colapso de células.
Há dois tipos de gemas formadas em raízes: aquelas formadas naturalmente, denominadas gemas adicionais e, aquelas formadas em resposta a danos mecânicos ou à senescência, denominadas reparativas (Raju et al. 1966). Ao observar as raízes gemíferas não é possível distinguir, morfologicamente, se as gemas são adicionais ou reparativas, sendo necessárias análises anatômicas para distingüí-las (Appezzato-daGlória 2003). O mesmo foi observado para as protuberâncias de Vernonia oxylepis, as quais eram morfologicamente idênticas, porém podiam tratar-se de gemas ou raízes laterais. As gemas adicionais têm origem endógena, a partir do periciclo, nas fases iniciais do crescimento radicular e, portanto, estabelecem conexão vascular com o cilindro central já, as gemas reparativas, possuem diferentes sítios de origem e não estabelecem conexão vascular com o cilindro central da raiz de origem (Bosela \& Ewers 1997). Os diferentes sítios de origem de gemas a partir de raízes, relatados na literatura, estão relacionados com a capacidade de sobrevivência das espécies ao ambiente (Hayashi et al. 2001). Em Vernonia oxylepis as gemas se originam do periciclo proliferado e são reparativas, pois não há traço vascular entre a gema e a raiz de origem. Em Mandevilla illustris e em M. velutina, as gemas também são reparativas, porém se originam no câmbio de nódulos vasculares formados no parênquima floemático da raiz. Em outras espécies de Vernonia, já analisadas anatomicamente, a origem da gema depende da estrutura anatômica do sistema subterrâneo. Nas espécies providas de rizóforos as gemas são axilares, pois a estrutura é caulinar (Sajo \& Menezes 1986a; 1986b; Machado et al. 2004; Hayashi \& Appezzato-da-Glória 2005). No xilopódio de Brasilia sickii, o qual possui estrutura anatômica mista, a gema é formada a partir da proliferação do parênquima cortical (Paviani 1987).

Nas Asteraceae, os frutanos do tipo inulina encontram-se distribuídos, principalmente, no parênquima vascular (Tertuliano \& Figueiredo-Ribeiro 1993). Nas raízes tuberosas de Vernonia oxylepis, aqui analisada, os cristais de inulina estão presentes no parênquima de origem pericíclica já, nas raízes adventícias de Richterago Kuntze (Asteraceae), estão no córtex interno e no cilindro vascular. Nos rizóforos de Vernonia herbacea e V. platensis (Hayashi \& Appezzato-da-Glória 2005) e de Smallanthus sonchifolius (Machado et al. 2004) os cristais de inulina estão acumulados, principalmente, no parênquima cortical. Por sua vez, nas espécies de Vernonia, estudadas por Sajo \& Menezes (1986a), 
estão acumulados no parênquima proveniente de câmbios acessórios no interior do xilema secundário.

A capacidade de formação periódica de gemas reparativas em Vernonia oxylepis, associada à contração radicular e ao acúmulo de dois tipos de reserva, lipídios e frutanos, certamente são indicativos da adaptação dessa espécie às condições adversas do Cerrado.

\section{Agradecimentos}

À Fundação de Amparo à Pesquisa do Estado de São Paulo, pelo suporte financeiro (Programa Biota Proc. 00/12469-3) e Bolsa de mestrado à primeira autora (Proc. 01/12138-0); ao Prof. Dr. Vinícius Castro Souza, do Departamento de Ciências Biológicas, da ESALQ/USP, pela identificação do material botânico; à Dra. Denise Zanchetta, responsável pela Estação Ecológica de Itirapina do Instituto Florestal, pela autorização concedida para a coleta do material botânico; à Sra. Marli Soares, pelo apoio técnico.

\section{Referências bibliográficas}

Alberdi, M.; Bravo, L.A.; Gutiérrez, A.; Gidekel, M. \& Corcuera, L.J. 2002. Ecophysiology of Antarctic vascular plants. Physiologia Plantarum 115: 479-486.

Almeida, A.M.; Fonseca, C.R.; Padro, P.I.; Almeida Neto, M.; Diniz, S.; Kubota, U.; Braun, M.R.; Galdini Raimundo, R.L.; Anjos, L.A.; Mendonça, T.G.; Furtada, S.M. \& Lewinsohn, T.M. 2005. Diversidade e ocorrência de Asteraceae em cerrados de São Paulo. Biota Neotropica 5(2): http:/www.biotaneotropica.org.br.

Appezzato-da-Glória, B. 2003. Morfologia de sistemas subterrâneos: histórico e evolução do conhecimento no Brasil. Ribeirão Preto, Ed. Alexandre Sene Pinto.

Appezzato-da-Glória, B. \& Estelita, M.E.M. 1995. Caracteres anatômicos da propagação vegetativa de Mandevilla illustris (Vell.) Woodson e de M. velutina (Mart. ex Stadelm.) Woodson - Apocynaceae. Pp. 5-13. In: Anais do IX Congresso da Sociedade Botânica de São Paulo. Ilha Solteira 1995. Ilha Solteira, SBSP.

Appezzato-da-Glória, B. \& Estelita, M.E.M. 2000. The developmental anatomy of the subterranean system in Mandevilla illustris (Vell.) Woodson and M. velutina (Mart. ex Stadelm.) Woodson (Apocynaceae). Revista Brasileira de Botânica 23: 7-35.

Asega, A.F. \& Carvalho, M.A.M. 2004. Fructan metabolising enzymes in rhizophores of Vernonia herbacea upon excision of aerial organs. Plant Physiology and Biochemistry 42: 313-319.

Bosela, M.J. \& Ewers, F.W. 1997. The mode of origin of root buds and root sprouts in the clonal tree Sassafras albidum (Lauraceae). American Journal of Botany 84: 1466-1481.
Estelita-Teixeira, M.E. 1978. Desenvolvimento anatômico do sistema subterrâneo de Oxalis latifolia Kunth (Oxalidaceae) -II- Sistema Radicular. Boletim Botânica, Universidade de São Paulo 6: 27-38.

Figueiredo-Ribeiro R.C.L.; Dietrich, S.M.S.; Chu, E.P.; Carvalho, M.A.M.; Vieira, C.C.J. \& Graziano, T.T. 1986. Reserve carbohydrates in underground organs of native Brazilian plants. Revista Brasileira de Botânica 9: 159-166.

Figueiredo-Ribeiro R.C.L. 1993. Distribuição, aspectos estruturais e funcionais dos frutanos, com ênfase em plantas herbáceas do cerrado. Revista Brasileira de Fisiologia Vegetal 5: 203-208.

Hayashi, A.H.; Penha, A.S.; Rodrigues, R.R. \& Appezzatoda-Glória, B. 2001. Anatomical studies of shoot budforming roots of Brazilian tree species. Australian Journal of Botany 49: 745-751.

Hayashi, A.H. \& Appezzato-da-Glória, B. 2005. The origin and anatomy of rhizophores in Vernonia herbacea and V. platensis (Asteraceae) from Brazilian Cerrado. Australian Journal of Botany 53: 273-279.

Jensen, W.A. 1962. Botanical histochemistry: principle and practice. San Francisco, W.H. Freeman.

Johansen, D.A. 1940. Plant microtechnique. New York, McGraw-Hill Book Company.

Machado, S.R.; Oliveira, D.M.T.; Dip, M.R. \& Menezes, N.L. 2004. Morfoanatomia do sistema subterrâneo de Smallanthus sonchifolius (Poepp. \& Endl.) H. Robinson (Asteraceae). Revista Brasileira de Botânica 27: 115-123.

Melo-de-Pinna, G.F.A. \& Menezes, N.L. 2003. Meristematic endodermis and secretory structures in adventitious roots of Richterago Kuntze (Mutisieae-Asteraceae). Revista Brasileira de Botânica 26: 1-10.

Paviani, T.I. 1972. Estudo morfológico e anatômico de Brasilia sickii G.M. Barroso: I. Revista Brasileira de Biologia 32: 451-472.

Paviani, T.I. 1977. Estudo morfológico e anatômico de Brasilia sickii G.M. Barroso. II: Anatomia da raiz, do xilopódio e do caule. Revista Brasileira de Biologia 37: 307-324.

Paviani, T.I. 1978. Anatomia vegetal e cerrado. Ciência e Cultura 30: 1076-1086.

Paviani, T.I. 1987. Anatomia do desenvolvimento do xilopódio de Brasilia sickii G.M. Barroso. Estágio inicial. Ciência e Cultura 39: 399-405.

Raju, M.V.S.; Coupland, R.T. \& Steeves, T.A. 1966. On the occurrence of root buds on perennial plants in Saskatchewan. Canadian Journal of Botany 44: 33-37.

Rizzini, C.T. \& Heringer, E.P. 1961. Underground organs of plants from some southern Brazilian savannas, with special reference to the xylopodium. Phyton 17: 105-124.

Rizzini, C.T. 1965. Estudos experimentais sobre o xilopódio e outros órgãos tuberosos de plantas do cerrado. Anais da Academia Brasileira de Ciências 37: 87-113.

Sajo, M.G. \& Menezes, N.L. 1986a. Anatomia do rizóforo de espécies de Vernonia Schreb. (Compositae), da Serra do Cipó, MG. Revista Brasileira de Biologia 46: 189-196. 
Sajo, M.G. \& Menezes, N.L. 1986b. Origem e crescimento do rizóforo em espécies de Vernonia Schreb. (Compositae) da Serra do Cipó, MG. Revista Brasileira de Biologia 46: 197-202.

Sakai, W.S. 1973. Simple method for differential staining of paraffin embedded plant material using toluidine blue O. Stain Technology 48: 247-249.
Strasburger, E. 1913. Handbook of practical botany. $7^{\text {th }}$ ed. London, George Allen.

Tertuliano, M.F. \& Figueiredo-Ribeiro, R.C.L. 1993. Distribution of fructose polymers in herbaceous species of Asteraceae from the cerrado. New Phytologist 123: 741-749.

Vijn, I. \& Smeekens, S. 1999. Fructan: more than a reserve carhohydrate? Plant Physiology 120: 351-359. 